\title{
Competency-Based Assessment in Pediatrics for the New Undergraduate Curriculum
}

\author{
Piyush Gupta, ${ }^{1}$ Dheeraj Shah, ${ }^{1}$ TeJinder Singh ${ }^{2}$ \\ From Department of Pediatrics, ${ }^{1}$ University College of Medical Sciences, Delhi; and ${ }^{2}$ Departments of Pediatrics and Medical \\ Education, SGRD Institute of Medical Sciences and Research, Amritsar, Punjab. \\ Correspondence to: Prof Piyush Gupta, Professor and Head, Department of Pediatrics, University College of Medical Sciences \\ (University of Delhi), Dilshad Garden, Delhi 110 095.prof.piyush.gupta@gmail.com
}

\begin{abstract}
Medical Council of India (MCl) implemented competency-based curriculum for undergraduate medical education nationwide in 2019 , with assessment of competencies being its integral component. The curriculum has outlined some broad principles and components of assessment, but the process and schedule for formative and summative assessment is to be decided by the universities and institutions. In this document, we summarize the recommendations for the subject of Pediatrics, and propose an assessment model for summative assessment that can be adapted/adopted by universities and institutions. Few basic principles of formative assessment have been shared, the implementation of which may be the main challenge for the institutions. It is important to develop the capacity of the faculty for conducting the assessment under the ambit of principles of competency-based curriculum.
\end{abstract}

Keywords: CBME, Curriculum, Medical education, University examinations.

Published online: April 20, 2021; PII: S097475591600315

$\mathrm{T}$ he Medical Council of India (MCI) has recently introduced competency-based curriculum for undergraduate medical education [1]. Robust assessment process is a vital part of its implementation as this curriculum is outcome oriented (acquisition of competencies) rather than process oriented. Competencies are defined as habitual and consistent use of knowledge, skills, attitudes and communication related to a clinical problem [2]. A perusal of this definition indicates that competency-based assessment cannot be a one-time process or a year-end examination; rather it has to span over a period of time to assess if the student is using them 'habitually and consistently.' The MCI guidelines have rightly emphasized the role of formative and internal assessment in acquisition and development of competencies. We present an overview of assessment guidelines for the subject of pediatrics by erstwhile MCI and propose a model for competency-based assessment. We have refrained from any critique of these guidelines. Both internal and summative assessments must be planned and implemented by respective universities and/or colleges, with few variations. The underpinning concepts of competency-based assessment have earlier been described in detail [3].

\section{INTERNAL ASSESSMENT}

Internal assessment, though vital, has been a bone of contention due to its 'subjective' nature. However, expert subjective judgments can be as reliable as highly objective and standardized assessments. A 'Quarter model' of internal assessment had been proposed [4] to ensure that no test, teacher, tool or context contributes to more than $25 \%$ to the total. MCI recommendations have also proposed a minimum of three tests for pre- and paraclinical subjects and minimum of two tests per professional year for the clinical subjects supplemented by unlimited opportunities for formative ongoing assessments [1,5]. It is important to involve all teachers in the department in the assessment process to dilute subjectivity, to expose students to different ways of thinking about a problem, and to train junior teachers in assessment. A good record keeping in the form of a logbook or e-portfolio (an electronic document that contains a log of learning activities as well as an evidence of learning from those) is important to provide developmental feedback to the students, especially for clinical skills [6].

A welcome change in the new curriculum is that internal assessment marks are shown separately in the final report and are not added to marks of the University summative examinations. This provides us better opportunities for using internal assessment as multiple low stake assessment to assess acquisition of most competencies. A satisfactory performance in internal assessment $(50 \%$ combined in theory and practical, minimum $40 \%$ in each) is still required to be eligible for appearing for university examinations $[1,5]$. However, it is 
simultaneously imperative to develop a feedback mechanism not only to help students acquire the competencies but also to revisit and modify teachinglearning methods and strategies.

There are 406 competencies listed in the subject of Pediatrics out of which 23 are competencies that require certification at 'Perform' level (Table I) [7]. As the competency-based system focuses on integration of all domains of learning (cognitive, psychomotor, affective) with communication skills, it is not possible to assess the acquisition of competencies just by internal or intermittent summative examinations. While it is relatively easy to implement the summative component of internal assessment, a structured mechanism for formative component with regular monitoring of students' behavior and assessment of patient records and logbooks remains a challenge. The feasibility-criticality matrix provided in the Skill module [8] of erstwhile MCI can be used as a guideline to classify what should be tested during final examinations and what can be left for internal part. As a general rule, all certifiable skills (Table I) should be included in internal assessment while others can be included in the formative part. Similarly, teacher to student ratio, and availability of patients and skill labs should be considered to decide whether to use real patients or manikins. A high level of motivation and coordination among the teachers is required so that assessment is not taken as a formality or burden but is utilized to monitor acquisition of competencies as well as the department's teaching-learning program. Up to $20 \%$ marks in internal assessment have been allocated to logbooks and this could be used as a handle to encourage formative assessments. Assessment module by MCI [5], serves as a guide for development of formative assessment which may be personalized by respective Universities and institutions using the available resources [9].

A major issue with internal assessment has been

Table I List of Competencies in Pediatrics That Require Certification (Perform Level)

\begin{tabular}{lr}
\hline Competency & No. required \\
\hline Perform Anthropometric measurements, document in growth charts and interpret & 3 \\
Perform Developmental assessment and interpret & 3 \\
Observe the correct technique of breast feeding and distinguish right from wrong techniques & 3 \\
Calculate BMI, document in BMI chart and interpret & 3 \\
Assess patient for fitness for immunization and prescribe an age-appropriate immunization schedule & 5 \\
Perform NG tube insertion in a manikin & 2 \\
Perform IV cannulation in a model & 2 \\
Perform Intraosseous insertion in a model & 2 \\
Assess airway and breathing: recognize signs of severe respiratory distress. Check for cyanosis, severe chest indrawing, grunting & 3 \\
Assess airway and breathing. Demonstrate the method of positioning of an infant \& child to open airway in a simulated & 3
\end{tabular}

Assess airway and breathing: administer oxygen using correct technique and appropriate flow rate 3

Assess airway and breathing: perform assisted ventilation by bag and mask in a simulated environment 3

Check for signs of shock i.e. pulse, Blood pressure, CRT 3

Secure an IV access in a simulated environment 3

Choose the type of fluid and calculate the fluid requirement in shock 3

Assess level of consciousness and provide emergency treatment to a child with convulsions/coma 3

Assess for signs of severe dehydration 3

Provide BLS for children on a manikin 3

Perform and interpret Urine DipStick for Sugar 3

Identify deviations in growth and plan appropriate referral 2

Identify a BCG scar 3

Interpret a Mantoux test 3

Perform AFB staining 3

Compiled from National Medical Council. Competency Based Undergraduate Curriculum for the Indian Medical Graduate, 2018. Vol. II [7]

INDIAN PEDIATRICS 
'subjectivity' and 'bias', which prevents us from making its full use. An earlier proposed quarter model [4] provides useful guidelines. Similarly, many components of programmatic assessment (PA) [10] can also be incorporated, like utility of assessment [11] rather than attributes of individual tool or assessment, and using every assessment to provide liberal feedback to the students. Feasibility and educational impact are important attributes for both formative as well as internal assessment. To obviate the issues of subjectivity and bias, it is better to have all teachers of the department involved in the process [4]. Since senior residents are also considered teachers as per MCI guidelines, they can be used for many formative events, especially those involving procedural skills.

\section{UNIVERSITY EXAMINATIONS}

University examinations may not be the ideal way to assess competencies due to logistic concerns. However, they are extremely useful tools to help in quality maintenance and conducting assessment. Graduate Medical Education Regulations (GMER) 2019 [1] and MCI Assessment module [5] lay down the principles and broad structure for the university examinations. Table II summarizes the guidelines from these modules for summative assessment in the subject of Pediatrics [1,5,7]. Different universities may adopt different combinations of the same. A model for summative examination for undergraduates in Pediatrics is proposed in Box I. The scheme is in consonance with the proposals made by MCI. A key feature of this process would be to assess higher levels of Miller pyramid [12], aligning assessment with the competencies, and analyzing the analytical, synthetic and problem-solving skills of the students. The
MCI module on assessment [5] has given few examples, which can be built upon. Examiner orientation, framing scenario-based questions, and having model questions to address various levels of Bloom Taxonomy are some inputs which need to be provided.

\section{THE WAY FORWARD}

Though introduction of competency-based curriculum for undergraduate medical education is a desirable and long-due change, it comes packaged with a lot of challenges. Assessment and documentation of acquisition of competencies will require a high degree of dedication, motivation and input in terms of time and resources, especially in busy clinical departments with perpetual shortage of faculty. The capacity building of the existing as well as new medical teachers is also a huge task. MCI has mandated participation in Curriculum Implementation Support Program (CISP) for all medical teachers [5], which will only be a sensitization. Moreover, the SARS CoV-2 pandemic in the years 2020 and 2021 has posed unique challenges and has interrupted the suggested sequence of teaching-learning and/or assessment for at least two successive batches of undergraduate students. Academic societies can play a definite role in capacity building of faculty and in helping the departments to develop appropriate teachinglearning methods and assessment strategies. As the first step towards uniformity, Indian Academy of Pediatrics (IAP) has already released learning objectives based on MCI competencies [13]. These will be useful for implementation of the competency-based curriculum for the first batch of MBBS students admitted in 2019. The next challenge is to develop an assessment model linked with competencies, especially the formative component

Table II Assessment for Competency Based Curriculum in Pediatrics

\begin{tabular}{|c|c|c|c|}
\hline & \multirow[t]{2}{*}{ Phase 2/II professional } & \multicolumn{2}{|c|}{ Phase 3/III professional } \\
\hline & & Part 1 & Part 2 \\
\hline \multicolumn{4}{|l|}{ Internal assessment } \\
\hline Theory exams & EOP only $b$ & Twice + EOP & Twice + EOP \\
\hline Attendance $^{a}$ & $75 \%$ & $75 \%$ & $75 \%$ \\
\hline Practical exams & End of I clinical posting (2 wk) & End of II clinical posting ( $4 \mathrm{wk}$ ) & End of III clinical posting (4 wk) \\
\hline Attendance $^{a}$ & $80 \%$ & $80 \%$ & $80 \%$ \\
\hline University examination & - & - & \\
\hline Theory & - & - & 1 paper: 100 marks \\
\hline Practical/oral/clinical & & & 100 marks \\
\hline Pass criteria & None & None & $\begin{array}{l}50 \% \text { separately in theory and } \\
\text { practical }\end{array}$ \\
\hline
\end{tabular}

${ }^{a}$ Attendance required; ' $b$ s the students are not taught pediatrics theory during this phase, the theory assessment should cover the 'knowledge' part of clinical and practical skills taught during this phase; EOP: End of posting. 


\section{Box I A Suggested Plan for Summative Assessment (University Examination) in Pediatrics}

Target: Final Year MBBS Student; Type: Summative; Timeline: At the end of Phase 3 (Third Professional - Part II examination)

Theory: 100 marks/duration 3 hours

1. There will be one theory paper with two PARTS A and B.

2. PART A will be only multiple choice questions (MCQ) and PART B will have two Sections I and II.

3. Questions to be framed as per guidelines given in Assessment Module of CISP

\begin{tabular}{|c|c|c|c|c|c|}
\hline Part/time & Section & Type of questions & Questions & Syllabus/ content ${ }^{a}$ & Marks allotted \\
\hline $\mathrm{A} / 30 \mathrm{~min}$ & & MCQ & 20 & Entire syllabus & 20 \\
\hline \multirow[t]{3}{*}{$\mathrm{B} / 150 \mathrm{~min}$} & I & $\begin{array}{l}\text { Structured essay/long answer } \\
\text { question (LAQ) }\end{array}$ & 1 & $\begin{array}{l}* \text { Topics } 1-20+1 \text { SAQ } \\
\text { from AETCOM }\end{array}$ & $15+25=40$ \\
\hline & & Short answer question (SAQ) & 5 & & \\
\hline & II & Structured essay/LAQ/SAQ & 15 & *Topics 21-35 & $15+25=40$ \\
\hline
\end{tabular}

Practical: 100 marks

4. To be conducted in batches of not more than 40 per day

5. The idea is to have multiple examinations by multiple examiners to eliminate bias. At the end of the day, the student should have been exposed to all the examiners available on that day.

6. Number of examiners will be according to the number of students in the batch. Up to 12 students in a day, 2 examiners; 13-25 students: 4 examiners: 26-40 students: 6 examiners. Of all examiners, 50\% should be external examiners.

7. Each examiner to assess a different case rather than putting many examiners on one case. This allows more number of cases to be included and helps in building validity and reliability of assessment.

8. Broadly assessment will consist of 2 pediatric cases ( 22 marks each), 1 newborn case ( 16 marks), OSCE ( 4 stations of 5 marks each), and Viva-voce (4 stations of 5 marks each).

A. Pediatric cases (conventional case presentation)

Each student will get two cases each as follows:

Case 1: General Pediatrics (22 marks)

- $\quad$ Case examination (including direct observation) 20 minutes and interaction with examiner: 15 min

Case 2: Systemic Pediatrics (22 marks)

- $\quad$ Case examination (including direct observation) 20 minutes, and 20 minutes and interaction with examiner: 15 min

Both cases should be taken by different set of examiners. The examiners should ensure assessment on direct observations of various competencies including history taking, examination, and counseling. This will improve the validity of assessment.

B. Newborn case (10 minutes station) (extended OSCE cum directly observed Station)

This case will be conducted like an extended OSCE cum directly observed station. In effect, it means increasing the time for each station and using a part of that time observing the student taking history or performing the examination. It's assessment will include Directly observed history taking/examination of newborn/counseling of mother. Directly observed procedural skills on Neonatal resuscitation will also be assessed on manikin and related equipment.

\section{OSCE (4 stations each of 5 min, Unobserved)}

Station 1: $X$-rays/ECG/ABG/Instrument

Station 2: Clinical spotters/photographs with tasks or questions related to diagnosis, management or prevention Station 3: Video of a Clinical Problem/outpatient case scenario/counseling

Station 4: Emergency case scenario/procedures

The OSCE stations should be designed to assess clinical competence and should not become an assessment of theory alone.

D. Viva-voce (4 stations each of $5 \mathrm{~min}$ )

- Viva/oral examination should assess approach to patient management, emergencies, attitudinal, ethical and professional values.

- Candidate's skill in interpretation of common investigative data, $X$-rays, identification of specimens, ECG, etc. may also be assessed in coordination with OSCE.

${ }^{a}$ As outlined in CBME document [5] 
in form of its structure, tools (e.g., logbook/portfolio), settings and schedule.

Contributors: PG: conceptualized the paper. All authors contributed to drafting and editing the article, and approval of the final manuscript.

Funding: None; Competing Interests: None stated.

\section{REFERENCES}

1. Board of Governors in Super-Session of Medical Council of India. Regulations on Graduate Medical Education (Amendment), 2019. Accessed October 12, 2020. Available from: https://www.mciindia.org/ActivitiWebClient/open/getDocument?path=/Documents/Public/Portal/Gazette/GME-06.11. 2019.pdf

2. Epstein RM, Hundert EM. Defining and assessing professional competence. JAMA. 2002;287:226-35.

3. Modi J, Gupta P, Singh T. Competency-based medical education, entrustment and assessment. Indian Pediatr. 2015;52:415-20.

4. Singh T, Anshu, Modi JN. The quarter model: a proposed approach for in training assessment of undergraduate students in Indian medical schools. Indian Pediatr. 2012;49:871-6.

5. Medical Council of India. Assessment: Module-3. Curriculum Implementation Support Program, 2019. Accessed Feb 12, 2021. Available from: https://www.nmc.org.in/wp-content/up
loads/2020/08/Module_Competence_based_02.09.2019.pdf 6. Joshi MK, Gupta P, Singh T. Portfolio-based learning and assessment. Indian Pediatr. 2015;52:231-5.

7. Medical Council of India. Competency Based Undergraduate Curriculum for the Indian Medical Graduate, 2018. Vol. II. Accessed February 12, 2021. Available from:https://www. nmc.org.in/wp-content/uploads/2020/01/UG-CurriculumVol-II.pdf

8. Medical Council of India. Skills Training Module for Undergraduate Medical Education Program, 2019. Accessed December 21, 2020. Available from: https://www.nmc.org.in/ wp-ontent/uploads/2020/08/Skill-Module_23.12.2019.pdf

9. Singh T. Formative assessment: Assessment for learning. In: Singh T, Anshu (eds). Principles of assessment in medical education. 1st ed. Jaypee Brothers, 2012.p. 25-30.

10. Humphrey-Murto S, Wood TJ, Ross S, et al. Assessment pearls for competency-based medical education. J Grad Med Educ. 2017;9: 688-91.

11. van der Vleuten CPM, Schuwirth LWT. Assessing professional competence: from methods to programs. Med Educ. 2005;39: 309-17.

12. Miller GE. The assessment of clinical skills/competence/performance. Acad Med. 1990;65:S63-7.

13. Singh T, Gupta P. Indian Academy of Pediatrics releases uniform learning objectives for competency-based curriculum in undergraduate Pediatric education. Indian Pediatr. 2020;57:182-3. 